\title{
A dívida pública do Estado de Santa Catarina entre 1935 e 2008
}

\author{
Andrey Jean Mattos Diniz* \\ João Rogério Sanson**
}

\begin{abstract}
RESUMO - Entre 1935 e 2008, a dívida pública de SC foi sustentável a maior parte do tempo, fugindo disso nos primeiros anos desse longo período e entre o Plano Cruzado e o Plano Real. Considerando-se as provisões de aposentadoria, isso volta a ocorrer a partir de 2007. O estudo faz parte de um projeto mais amplo de construção de séries históricas das finanças públicas do Estado de Santa Catarina.
\end{abstract}

Palavras-chave: Dívida pública. Santa Catarina. Séries históricas.

Séries históricas sobre as finanças públicas do Estado de Santa Catarina são difíceis de construir, pois os dados estão espalhados em diversas fontes. No presente artigo, ilustramos uma série de dados, completada recentemente, sobre a dívida pública do Estado para o período de 1935 a 2008. Ao mesmo tempo, esboçamos uma análise da série para demonstrar seu potencial em futuros estudos de história econômica regional.

Um projeto inicial do IPEA procurou levantar séries longas de despesas de pessoal para se entender a crise fiscal dos estados brasileiros nos anos 80 e 90 . Nesse contexto, o primeiro estudo da série sobre o Estado de Santa Catarina foi o de Sanson e Seabra (1998). Desse trabalho resultaram outros, começando por Burgugi-Brasil (2001), que ajudam a montar um painel das finanças públicas do Estado de Santa Catarina, cobrindo desde 1835 até $2008 .{ }^{1}$

O período coberto no presente estudo é de 1935 a 2008, que é justificado pela disponibilidade de séries consistentes de dívida e receita. Os dados de balanço foram coletados incialmente por Burgugi-Brasil (2001) para o período de 1964 a 1999. Mota (2002) e Mignoni (2006) cobrem o período anterior desde 1935, compatibilizando os diferentes sistemas de contas. Diniz (2009) atualizou e conferiu os dados junto aos balanços e relatórios disponíveis na Secretaria de Estado da Fazenda e na Assembleia Legislativa de Santa Catarina.

\footnotetext{
* Bacharel em Economia pela Universidade Federal de Santa Catarina (UFSC). Endereço eletrônico: andreydiniz@ymail.com.

** PhD pela Universidade Vanderbilt, EUA. Professor titular do Departamento de Economia da Universidade Federal de Santa Catarina (UFSC). Endereço eletrônico: jrsanson@mbox1.ufsc.br.

1 Alguns desses estudos estão disponíveis em http://www.tinyurl.com/ya9dafo e em http://www.tinyurl.com/yclr55b. Silva (2008, seção 1.2) lista esses trabalhos.
} 
$\mathrm{Na}$ Secretaria de Estado da Fazenda, foram verificados e atualizados os dados referentes às receitas e dívidas em balanços e demonstrações dos exercícios de 1950 a 1954, das prestações de contas dos exercícios de 1955 a 1964, exceto 1960, retirados de Mota (2002), e, por último, dados coletados dos balanços gerais dos exercícios de 1964 a 2008. Dados sobre despesas de 2000 a 2008 foram também coletados nos balanços gerais dos exercícios dos respectivos anos. No Centro de Memórias da Assembléia Legislativa do Estado de Santa Catarina, foram consultados os relatórios dos governadores de Santa Catarina no período de 1929 a 1940.

Exploramos aqui a relação entre Dívida Total e Receita Total. ${ }^{2}$ A ideia básica é acompanhar a sustentabilidade da dívida estadual. A Lei de Responsabilidade Fiscal, de 2000, complementada por resolução do Senado de 2001, estabeleceu como sustentável uma razão aproximadamente igual a dois para essa razão. Esse número levou em consideração as perspectivas de crescimento da receita estadual, das taxas de juros reais da época, na faixa dos dois dígitos, e da capacidade dos governos estaduais gerarem superávits primários. ${ }^{3}$

A razão dívida total sobre receita total começa em 3,23 em 1935 ainda em plena Grande Depressão, Conforme inlustrado pelo gráfico 1. Essa razão cai continuamente até 1957, quando fica pouco abaixo de um décimo. É o menor valor da série, no período do Governo de Juscelino Kubitschek, que assumira a presidência em 1956. A partir de 1958, a razão dívida-receita volta a crescer, entremeada por pequenas flutuações, embora só vá atingir níveis altos nos anos 80 .

GRÁFICO 1 - SANTA CATARINA - RELAÇÃO DÍVIDA TOTAL-RECEITA TOTAL - 1935 A 2008

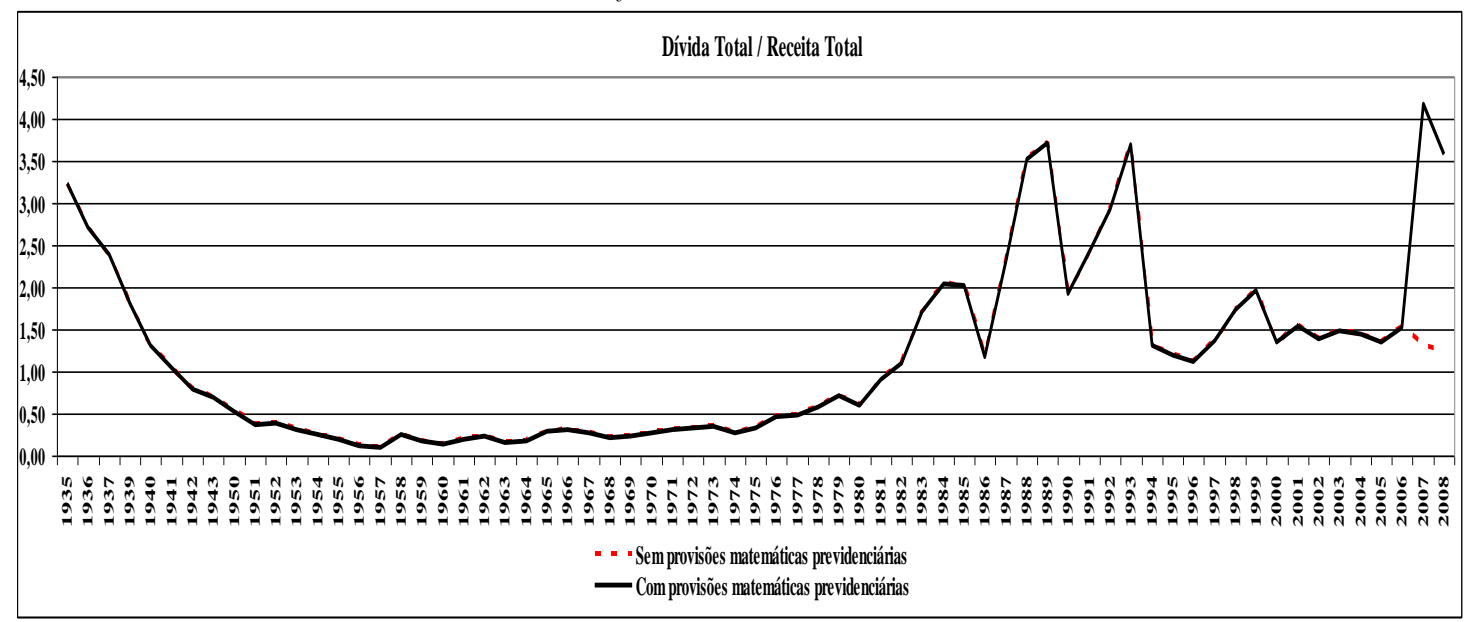

FONTE: Burgugi (2001), Mota (2002), Mignoni (2006) e Diniz (2008).

\footnotetext{
${ }^{2}$ Diniz (2009) ilustra também como evoluiu a relação Dívida Fundada e Receita Corrente.

3 Ver Mora e Giambiagi (2007), especialmente, p.480. Nesse estudo, há simulações para diferentes valores de taxas reais de juros com vistas a avaliar a sustentabilidade da dívida estadual.
}

60 
Um dos motivos que gerou o crescimento da dívida foi a euforia econômica dos anos JK, reforçada pelo Governo Celso Ramos em Santa Catarina. Esse governador implementou um plano de desenvolvimento ambicioso a partir de 1961, inaugurando uma estrutura estatizada, voltada para o crescimento de longo prazo. Isso incluiu um banco estatal, o Banco do Estado de Santa Catarina (BESC), a Universidade para o Desenvolvimento do Estado de Santa Catarina (UDESC), uma concessionária de energia, as Centrais Elétricas de Santa Catarina (CELESC) entre outras ações. Em fevereiro de 1966, quando assume o governador seguinte, eleito diretamente, a Dívida Total atinge aproximadamente um terço da Receita Total, ainda uma razão facilmente sustentável em termos de serviço da dívida.

$\mathrm{Na}$ primeira década dos governos militares, a razão dívida-receita mantém-se oscilante ao redor de um terço. Nesse período, efetiva-se a reforma do sistema tributário e se introduzem mudanças no mercado financeiro com a correção monetária de títulos públicos. Contudo, isso não se traduziu em maior financiamento via dívida por parte do Estado de Santa Catarina.

Somente nos anos seguintes à primeira crise do petróleo, em 1974, a razão volta a crescer sistematicamente, aproximando-se da unidade após a segunda crise do petróleo, em 1979, e atingindo o valor dois em 1984. Isso pode ser considerado um reflexo da crise fiscal do Estado brasileiro e do descontrole inflacionário iniciado nessa década. Por sinal, o período da alta inflação tende a superestimar a razão dívida-receita, quando esta é calculada a partir de valores nominais como neste estudo. Isso decorre de a dívida estar definida a preços de dezembro, enquanto que a receita reflete a inflação média do ano. O deflacionamento da série, pelo menos para o período de alta inflação, deverá ser feito em estudos que necessitem de maior precisão do que a avaliação qualitativa deste estudo.

Com o Plano Cruzado, em 1986, a razão cai temporariamente para próximo da unidade. Volta a subir e atinge 3,7 em 1989. O Plano Collor a derruba novamente, embora apenas para a razão dois, voltando a crescer no ano seguinte e atingindo novamente $3,7 \mathrm{em}$ 1993. Com o Plano Real, volta a cair. As crises financeiras do final da década repercutiram em Santa Catarina e a dívida subiu mais rápido do que a receita. Uma das razões para isso foi também a alta emissão de títulos da dívida sob a justificativa de cobrir precatórios.

Em 1998, o estado é socorrido pelo Governo Federal, renegociando sua dívida sob a condição de seguir a política nacional de estabilização macroeconômica. ${ }^{4}$ Uma das

\footnotetext{
${ }^{4}$ Lopreato (2002, p.221-222) apresenta os detalhes das negociações entre a União e os Estados.
} 
consequências foi, inicialmente, a federalização do BESC, recentemente incorporado pelo Banco do Brasil. O controle federal é então mais direto, embora a evidência vista acima mostre que o estado acompanhava os ciclos econômicos do país também nas finanças públicas. O que de fato houve, com a renegociação e depois com a Lei de Responsabilidade Fiscal, foi um ajuste fino.

Em 2007 e 2008, a razão novamente atinge níveis altos. A explicação para isso é a inclusão de cálculos das provisões matemáticas previdenciárias, adotadas a partir de então como parte da dívida total. Sem essas provisões, a tendência era de queda na razão.

A comparação dessa série com a da razão entre Dívida Fundada e a Receita Corrente mostra que as duas séries têm comportamento qualitativo similar. A variabilidade, contudo, é diferente. Mais detalhes podem ser encontrados em Diniz (2009).

Uma característica interessante da série de Dívida Total é o fato de a razão dívidareceita ter atingido um nível médio mais alto após a estabilização da economia. Com exceção do final da déca de 1990, a razão estabilizou ao redor de 1,5. É como se o descontrole inflacionário tivesse motivado tolerância a um nível de endividamento mais alto do que no longo período anterior à década de 80 em Santa Catarina. Será preciso esperar alguns anos para verificar se esse é um nível de equilíbrio. 


\section{REFERÊNCIAS}

BURGUGI-BRASIL, M. N. Evolução das receitas, despesas e dívida pública de Santa Catarina: 1964 a 1999. Monografia (Graduação em Ciências Econômicas) - Departamento de Economia, Universidade Federal de Santa Catarina, Florianópolis, 2001.

LOPREATO, F. L. C. O colapso das finanças estaduais e a crise da federação. São Paulo: Editora da UNESP; Instituto de Economia, UNICAMP, 2002.

MIGNONI, T. Evolução das Receitas, Despesas e Dívida Pública de Santa Catarina: 1931 a 1949. Monografia (Graduação em Ciências Econômicas) - Departamento de Economia, Universidade Federal de Santa Catarina, Florianópolis, 2006.

MORA, M.; GIAMBIAGI, F. Federalismo e endividamento subnacional: uma discussão sobre a sustentabilidade da dívida estadual. Revista de Economia Política, v. 27, n. ${ }^{\circ}$ 3, p. 472-494, 2007.

MOTA. A J. Evolução das receitas, despesas e dívida pública de Santa Catarina: 1950 a 1970. Monografia (Graduação em Ciências Econômicas) - Departamento de Economia, Universidade Federal de Santa Catarina, Florianópolis, 2002.

SANSON, J. R.; SEABRA, F. Análise do gasto estadual de pessoal: Estado de Santa Catarina. Brasília: IPEA, 1998. Trabalho não publicado.

SILVA, M. ${ }^{a}$ A. S. A evolução da receita tributária do Estado de Santa Catarina no período 1929-2007. Monografia (Graduação em Ciências Econômicas) - Departamento de Economia, Universidade Federal de Santa Catarina, Florianópolis, 2008. 
